\title{
Total Synthesis of (+)-Spiroindimicin A via Asymmetric Palladium- Catalyzed Spirocyclization
}

\author{
Zhen Zhang, Sneha Ray, Leah Imlay, Lauren T. Callaghan, Hanspeter Niederstrasser, Prema Latha Mal- \\ lipeddi, Bruce A. Posner, Dawn M. Wetzel, Margaret A. Phillips, Myles W. Smith* \\ Department of Biochemistry, UT Southwestern Medical Center, 5323 Harry Hines Blvd., Dallas, TX 75390.
}

\section{Supporting Information Placeholder}

ABSTRACT: The spiroindimicins are a unique class of chlorinated indole alkaloids characterized by three heteroaromatic rings structured around a congested spirocyclic stereocenter. Here, we report the first total synthesis of $(+)$-spiroindimicin $\mathrm{A}$, which bears a challenging $\mathrm{C}$ $3^{\prime} / \mathrm{C}-5^{\prime \prime}$-linked spiroindolenine. We detail our initial efforts to effect a biomimetic oxidative spirocyclization from its proposed natural precursor, lynamicin $\mathrm{D}$, and describe how these studies shaped our final abiotic 9-step solution to this complex alkaloid built around a key asymmetric Pd-catalyzed spirocyclization. Scalable access to spiroindimicins $\mathrm{A}, \mathrm{H}$, and their congeners has enabled discovery of their activity against several parasites relevant to human health, providing potential starting points for new therapeutics for the neglected tropical diseases leishmaniasis and African sleeping sickness.

Dimeric tryptophan natural products represent an important class of compounds that has grown significantly in recent decades and contains several medicinally important members like rebeccamycin (1) and staurosporine (2) (Figure 1). ${ }^{1}$ Among this broad class, the spiroindimicins constitute a unique subset of non-planar molecules isolated from marine Streptomycetes. The inaugural members of this family, spiroindimicins A-D (36), were reported by Zhang and coworkers in 2012, followed by two monochlorinated members, spiroindimicins $\mathrm{E}$ and $\mathrm{F}(\mathbf{7 , 8})$, described by Luzhetskyy et al. in $2017 .^{2 \mathrm{a}, \mathrm{b}}$ Two deschloro congeners, spiroindimicins G and H (9, 10), were also isolated by the Zhang group from a bacterial mutant with an inactivated halogenase gene. ${ }^{2 \mathrm{c}} \mathrm{In}$ biological assays conducted thus far, the spiroindimicins displayed moderate cytotoxicity against several cancer cell lines $\left(\mathrm{IC}_{50}=9-44 \mu \mathrm{M}\right){ }^{2 \mathrm{a}, \mathrm{c}}$

Biosynthetically, the spiroindimicins are proposed to derive from the lynamicins, a previously isolated family of antibacterial alkaloids, ${ }^{3}$ via a spirocyclization of C-3' of one indole unit to either onto C-5" or C-2" of the neighboring indole fragment (Figure 2, top; spiroindimicin numbering, used throughout). This process transforms one indole into a spiroindolenine or -indoline and creates the congested C-3' quaternary spirocenter. In line with this hypothesis, lynamicins A (13) and D (12) were co-isolated with 3-6, and further biosynthetic investigations by the Zhang group have shed light on their biogenesis as halogenated dimers of tryptophan and their viability as precursors to $3-6 .{ }^{4,2 \mathrm{c}}$ At present, however, the enzyme(s) responsible for their oxidative spirocyclization remain unelucidated.
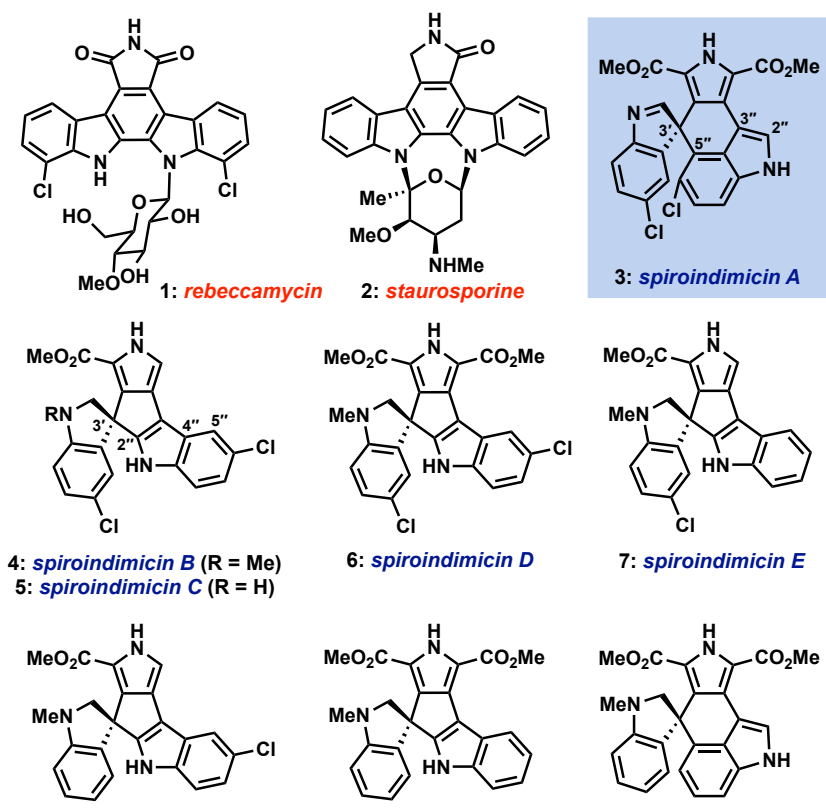

6: spiroindimicin D

7: spiroindimicin $E$

8: spiroindimicin F
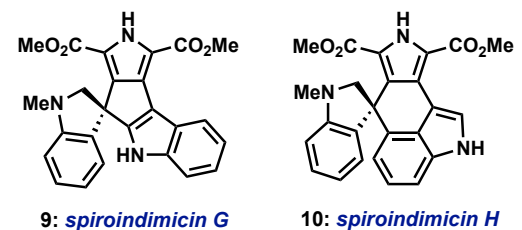

10: spiroindimicin $H$

Figure 1. Bioactive tryptophan dimers and the spiroindimicin family of alkaloids.

In light of their appealing structures and preliminary bioactivities, it is unsurprising that the spiroindimicins have attracted interest from the synthetic community. ${ }^{5}$ One prior racemic synthesis of spiroindimicins B (4) and C (5) has been reported by Sperry and Blair (15-16 steps), 
centering upon early-stage construction of the spirocenter via an intramolecular Heck reaction, followed by stepwise introduction of the remaining heterocycles. ${ }^{6}$ To the best of our knowledge, no synthetic studies toward either of the C-3'/C-5'--linked members, spiroindimicins A (3) and $\mathrm{H}(\mathbf{1 0})$, have been disclosed.

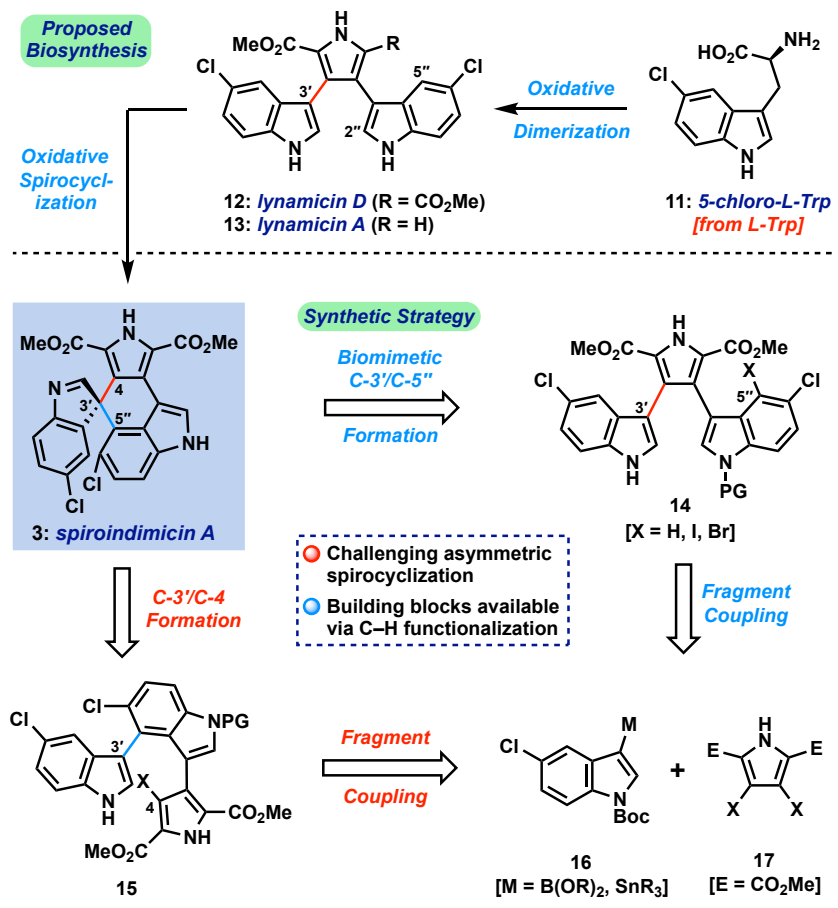

Figure 2. Spiroindimicin biosynthesis from L-tryptophan and our synthetic approach to spiroindimicin A (3).

Herein, we describe the first total synthesis of (+)-spiroindimicin A (3) relying upon a short, gram-scale preparation of a triaryl precursor and its Pd-catalyzed asymmetric spirocyclization. We apply the developed strategy to the preparation of spiroindimicin $H(\mathbf{1 0})$, lynamicins A and D $(13,12)$, and several structural analogues. Finally, with $>100 \mathrm{mg}$ of $\mathbf{3}$ in hand and a panel of congeners, we disclose their promising activity against the parasites Trypanosoma brucei, Plasmodium falciparum, and Leishmania amazonensis, causative agents of African trypanosomiasis (sleeping sickness), malaria, and leishmaniasis, respectively, diseases which constitute a serious and ongoing problem in the developing world. ${ }^{7}$

The main challenge associated with total synthesis of 3-10 arises in constructing their core quaternary spirocenters, especially in an enantiocontrolled fashion. ${ }^{8}$ This challenge is amplified when targeting spiroindimicin A (3), as this entails linking $\mathrm{C}-3^{\prime}$ of one indole unit to the less reactive $\mathrm{C}-5^{\prime \prime}$ position of the other indole ring (C-4 in indole nomenclature); in the case of the 4-9 the nucleophilic C-2" carbon is joined to this position. Our approach to spiroindimicin A (3, SPM A) is outlined in Figure 2 (bottom) and focused on two possible solutions to the challenging $\mathrm{C}-3^{\prime}$ spirocenter, namely a biomimetic final $\mathrm{C}-3^{\prime} / \mathrm{C}-5^{\prime \prime}$ spirocyclization (shown in blue) of a lynamicin D-type precursor (14), or a non-natural C-3'/C-
4 spirocyclization (shown in red) of an 'iso-lynamicin'type compound (15). In both cases, the spirocyclization might be effected in either an oxidative sense $(\mathbf{1 4}, \mathbf{1 5}, \mathrm{X}$ $=\mathrm{H})$ or via a functional handle $(\mathrm{X}=\mathrm{I}, \mathrm{Br}$, etc.). Control of the absolute stereochemistry in this key cyclization event remained a daunting prospect, however, given limited literature precedent. Precursors 14 and 15 should both be readily assembled via cross-coupling of appropriately functionalized heteroaryl fragments $\mathbf{1 6}$ and $\mathbf{1 7}$, themselves available via $\mathrm{C}-\mathrm{H}$ functionalization of inexpensive indole and pyrrole starting materials.

Our initial efforts focused on the biomimetic approach wherein oxidative spirocyclization of lynamicin D (12) might deliver either SPM A (3) directly, or possibly a spiroindolenine precursor to SPM D (6). For this purpose, we required a short and scalable synthesis of lynamicin D (12). 12 has been prepared once before in 6 steps (longest linear sequence) by Sarli and Nikolalaki utilizing a Suzuki coupling-based assembly of its triaryl moiety. ${ }^{9}$ Using their approach as inspiration, we were able to develop a shorter route to $\mathbf{1 2}$ leveraging the tools of $\mathrm{C}-\mathrm{H}$ functionalization. ${ }^{10}$ Thus, we could prepare pyrrole dibromide $\mathbf{1 8}$ via iron-catalyzed $\mathrm{C}-\mathrm{H}$ methoxycarbonylation ${ }^{11}$ of commercial ester 17, followed by dibromination (Scheme 1A). ${ }^{12}$ For the other partner, we could advance 5chloroindole (19) to C-3 boronic ester 20 through an efficient Ir-catalyzed $\mathrm{C}-\mathrm{H}$ borylation sequence. ${ }^{13} \mathrm{~A}$ highyielding Suzuki coupling using Buchwald's SPhos ligand $^{14}$ and removal of the Boc protecting groups delivered lynamicin D (12, 4 steps LLS). Using this scalable route we have been able to prepare over $1.7 \mathrm{~g}$ of $\mathbf{1 2}$, and additionally have achieved the synthesis of lynamicin A (13) via a monohydrolysis/decarboxylation sequence. ${ }^{15}$

Unfortunately, despite extensive investigation we have been unable to achieve formation of C-5" or C-2"-linked spiroindolenines from 12 under a range of oxidative conditions (reagent-based, electrochemical, photochemical; see SI for full details). Not surprisingly, $2^{\prime}, 2^{\prime \prime}$-linked indolocarbazole products such as $\mathbf{2 1}$ and $\mathbf{2 2}$ were often isolated. ${ }^{16}$ Similarly, efforts to utilize electronically differentiated monoprotected variants of $\mathbf{1 2}$ (e.g., 14, $\mathrm{PG}=\mathrm{Ts}$, Ac, Boc, cf. Fig. 2) or use the pyrrole ester/acid to direct C$5^{\prime \prime}$ functionalization also proved unsuccessful.

Given the challenge of achieving direct $\mathrm{C}-3^{\prime} / \mathrm{C}-5^{\prime \prime}$ oxidative spirocyclization, we planned to prepare an analogue with a suitable functional handle to allow for regioselective spirocyclization. While we initially targeted a C-5"-functionalized variant of lynamicin D (e.g., 14, X = Br, I, cf. Fig. 2), preliminary efforts toward its assembly proved difficult. Our ultimate solution involved switching the order of bond formations to C-3', where we first aimed to install the more challenging $\mathrm{C}-3^{\prime} / \mathrm{C}-5^{\prime \prime}$ bond in the form of an 'iso-lynamicin'-type precursor (15, Fig. 2). For this purpose, we prepared 4-iodoindole 24 in 3 steps on multigram scale from 4-nitroindole (23) by improving a 
Scheme 1. (A) Attempted biomimetic synthesis of spiroindimicin A (3) from lynamicin D (12); (B) Revised approach to 3 via Pd-catalyzed spirocyclization; (C) Synthesis of spiroindimicin H (10) and potentially undiscovered spiroindimicins

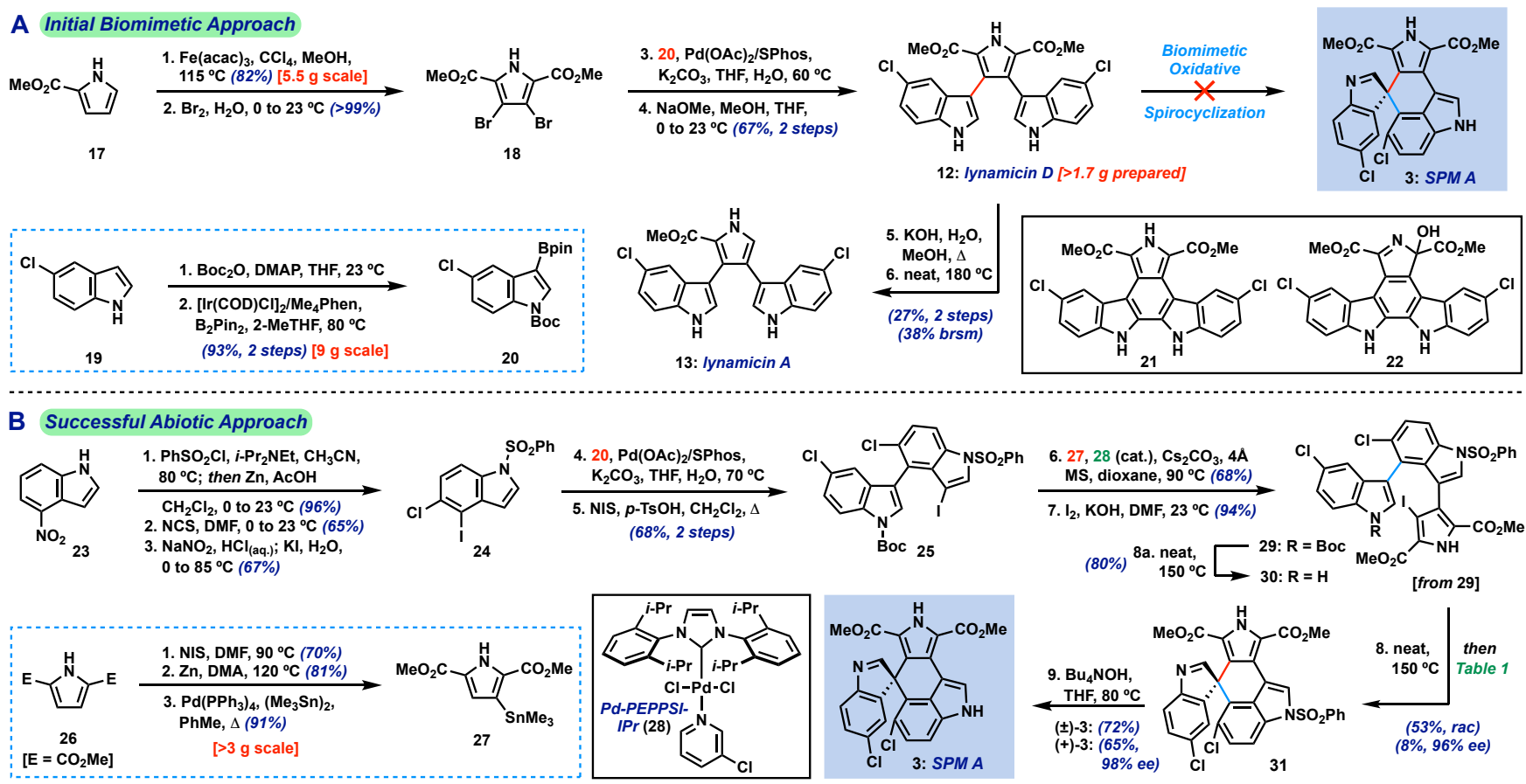

C Spiroindimicin H \& Analogue Synthesis

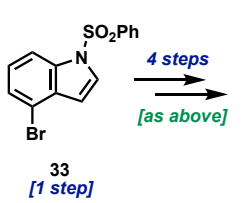<smiles>COC(=O)c1cc(-c2cn(S(=O)(=O)c3ccccc3)c3cccc(-c4c[nH]c5ccccc45)c23)c(C(C)=O)[nH]1</smiles>
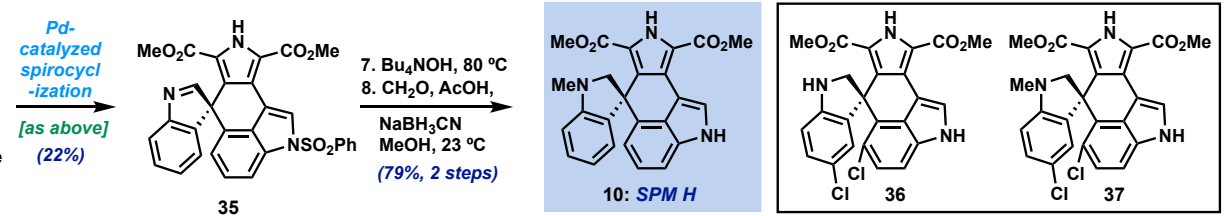

known sequence (Scheme 1B). ${ }^{17}$ The previously elusive $\mathrm{C}-\mathrm{C}$ bond could then be formed via Suzuki coupling with boronic ester $\mathbf{2 0}$ in quantitative yield. Hereafter, indole C3 iodination and a carefully optimized Stille coupling with pyrrole stannane 27 (prepared $^{18}$ in 3 steps from previously prepared 26) using Pd-NHC catalyst 28 gave a triaryl compound (not shown). A final iodination ${ }^{19}$ of the pyrrole ring and thermolytic Boc deprotection set the stage for the key spirocyclization, providing triaryl 30 which appears to exist as two separable atropisomers (dr $\sim 3: 1$ ) that slowly interconvert at room temperature.

With hundred-milligram quantities of $\mathbf{3 0}$ in hand, we explored the racemic spirocyclization to $\mathbf{3 1}$ using Pd-catalyzed conditions developed by You as a starting point. ${ }^{20}$ Although their optimal conditions ([Pd(allyl)Cl $]_{2} / \mathrm{PPh}_{3}$, $\mathrm{K}_{2} \mathrm{CO}_{3}, \mathrm{PhMe}, \Delta$ ) were unproductive, we did observe formation of $\mathrm{C}-2$ '-linked product $\mathbf{3 2}$ when employing $\mathrm{Cs}_{2} \mathrm{CO}_{3}$ as base in the presence of several phosphine ligands (Table 1). This 7-membered product appears to arise through direct $\mathrm{C}-2^{\prime}$ coupling rather than via $\mathrm{C}-3^{\prime}$ to $\mathrm{C}-2^{\prime}$ bond migration in desired spiroindolenine $31 .{ }^{21}$ Ultimately, we found that the ligand plays a crucial role in providing the desired connectivity, with NHC-Pd systems proving optimal: using Pd-PEPPSI-IPr $(\mathbf{2 8})^{22}$ as catalyst under otherwise identical conditions provided protected
SPM A (31) in 55\% yield (Table 1, entry 1). After screening over 40 chiral ligands (see SI for full details), we found that the use of chiral phosphoramidites provided the best balance between enantioselectivity and selectivity for 31 over 32 (entries 2-4). With optimal phosphoramidite $\mathbf{L 3},{ }^{21}$ enantioselectivity and especially yield were initially moderate $(9 \%, 75 \%$ ee; entry 4$)$ under our prior conditions. Ultimately, extensive investigations involving systematic variation of reaction parameters showed that the combination of both $\mathrm{Cs}_{2} \mathrm{CO}_{3}$ and $\mathrm{Ag}_{2} \mathrm{CO}_{3}$ as base (2.5 equiv each) and lowering of the temperature to $70{ }^{\circ} \mathrm{C}$ could effect spirocyclization in $14 \%$ yield and an excellent $98 \%$ ee (entries 5-8; see SI). Here, the modest yield of $\mathbf{3 1}$ is due to competitive formation of $\mathbf{3 2}$, as well as protodeiodination. Despite the moderate efficiency, to the best of our knowledge, this is the first report of a highly enantioselective arylative indole to spiroindolenine transformation, and the first use of such a reaction in natural product synthesis. ${ }^{20,24,25}$ 
Table 1. Optimization of Pd-catalyzed spirocyclization

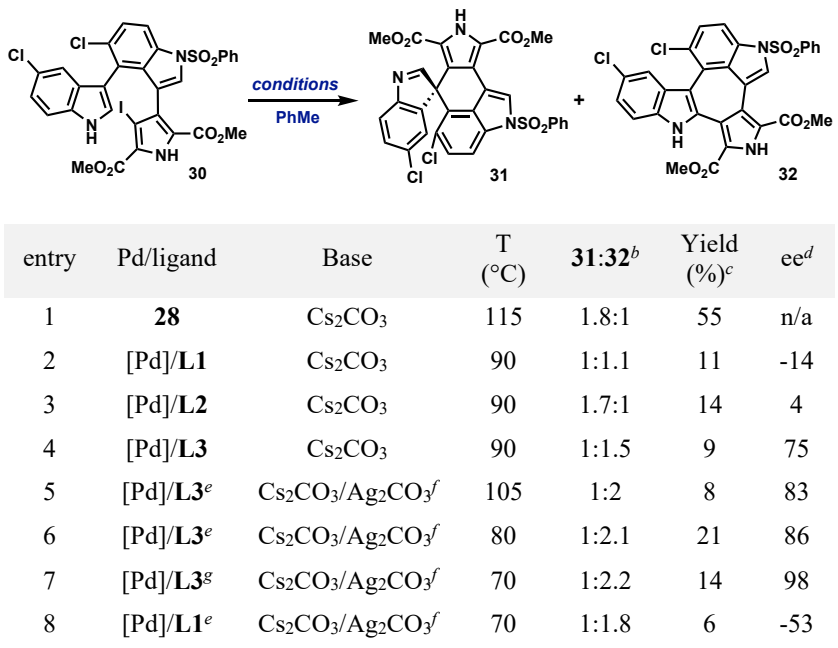

${ }^{a}[\mathrm{Pd}]=[\mathrm{Pd}(\mathrm{allyl}) \mathrm{Cl}] 2$; standard conditions: Pd source $(10 \mathrm{~mol} \%)$, ligand $(15$ $\mathrm{mol} \%)$, base (1.5 equiv); ${ }^{b}$ determined by ${ }^{1} \mathrm{H}$ NMR analysis of the crude reaction mixture; ${ }^{c}$ yield of isolated 31; determined by HPLC analysis; ${ }^{e}[\mathrm{Pd}] /$ ligand $(30 / 45 \mathrm{~mol} \%)$ prestirred in $\mathrm{PhMe}$ for $1 \mathrm{~h} ;{ }^{{ }^{2}} 2.5$ equiv each; ${ }^{g}[\mathrm{Pd}] /$ ligand $(40 / 60 \mathrm{~mol} \%)$.

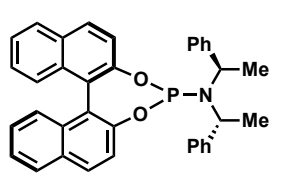

L1

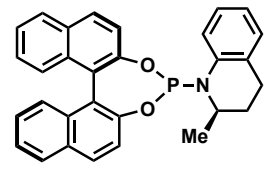

L2

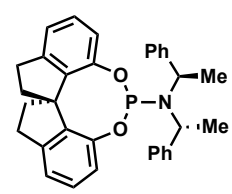

L3: (R)-SIPHOS-PE
Additionally, we found that Boc deprotection and spirocyclization could be conducted as a one-pot procedure by simply subjecting the residue remaining after thermolysis to the spirocyclization conditions $[( \pm)-31: 53 \%$; $(+)-$ 31: $8 \%, 96 \%$ ee]. A final removal of the benzenesulfonyl group of 31 with $\mathrm{Bu}_{4} \mathrm{NOH}$ at $80{ }^{\circ} \mathrm{C}$ delivered spiroindimicin A (3) $(65-72 \%)$, completing the first total synthesis of this target in 9 steps (longest linear sequence from commercial 4-nitroindole). Spectral data of our synthetic material matched those reported by Zhang and coworkers, and its chromatographic behavior was identical to an authentic sample (TLC; HPLC). The optical rotation was of the same sign and similar magnitude $\left\{[\alpha]^{26}{ }_{D}=\right.$ $+64.0(c=0.05, \mathrm{MeOH})$ for $98 \%$ ee; lit.: $[\alpha]^{20}{ }_{\mathrm{D}}=+46.49$ $(c=0.15, \mathrm{MeOH})\}$ confirming that we had prepared the natural enantiomer of 3. Utilizing our developed strategy, we have also been able to complete the first synthesis of spiroindimicin $\mathrm{H} \mathrm{(10)}$ in 8 steps from 4-bromoindole, as well as prepare the dihydrospiroindimicin A congeners 36 and 37, potentially as yet undiscovered natural products (cf. 4-10). Our synthetic efforts have yielded over $100 \mathrm{mg}$ of 3 to date.

Finally, with scalable access to spiroindimicin A (3) and a panel of related compounds, we have begun to explore their biological properties. Given that several tryptophan dimers, including staurosporine (2), have demonstrated antiparasitic activity, ${ }^{26}$ preliminary testing was conducted against the parasites Trypanosoma brucei, Plasmodium falciparum, and Leishmania amazonensis, ${ }^{8}$ revealing promising activity (Table 2). Specifically, SPM A (3) inhibits the growth of all three parasites $\left(\mathrm{EC}_{50}=1.3-11\right.$ $\mu \mathrm{M})$, with the potencies of natural $(S)-\mathbf{3}$, ent- $(R)-\mathbf{3}$, and racemic 3 being similar, suggesting a non-protein-based target. SPM H (10) and SPM A derivatives 36 and 37 are also active, demonstrating similar or slightly improved potencies in some cases. Lynamicin-type compounds showed activity, with $2^{\prime}, 2^{\prime \prime}$-linked indolocarbazole 21 displaying the highest potency against $T$. brucei $\left(\mathrm{EC}_{50}=\right.$ $0.37 \mu \mathrm{M})$. Several compounds are also active against both multidrug-resistant (Dd2) and drug-sensitive (3D7) strains of $P$. falciparum. Importantly, in most cases the compounds did not display significant cytotoxicity against mammalian HepG2 and RAW 264.7 cells (a macrophage cell line) at $10 \mu \mathrm{M}$; when toxicity was observed, reasonable selectivity was maintained in several cases (e.g., 21 vs T. brucei: selectivity index $\sim 12$ ). The efficacy observed against $T$. brucei and $L$. amazonensis is noteworthy and comparable to that of existing therapeutics. ${ }^{27,28}$ Natural spiroindimicin A $[(S)-3]$, in particular, may warrant further study against the neglected tropical disease leishmaniasis given its activity $\left(\mathrm{EC}_{50}=1.3 \mu \mathrm{M}\right)$ and lack of significant cytotoxicity in RAW cells.

In summary, we have reported the first asymmetric synthesis of (+)-spiroindimicin A (3). Our 9-step synthesis relies upon an efficient assembly of a triaryl scaffold with distinct connectivity to its natural precursor via crosscoupling, and a novel Pd-catalyzed asymmetric spirocyclization to construct the challenging $\mathrm{C}-3^{\prime} / \mathrm{C}-5^{\prime \prime}$-linked spiroindolenine in high enantiopurity. We have also prepared spiroindimicin $\mathrm{H}$ and lynamicins $\mathrm{A}$ and $\mathrm{D}$ in a concise fashion and tested the conversion of the latter to the spiroindimicins through biomimetic oxidative spirocyclization. Although unsuccessful, these studies did inform our ultimately successful approach to $\mathbf{3}$ using an alternate triaryl fragment. With meaningful quantities of spiroindimicin A (3) and its congeners now available, we have begun to explore their biological activity more broadly. Studies to date have unveiled antiparasitic activity that may provide a useful starting point for developing compounds to treat leishmaniasis and African trypanosomiasis. $^{27,28}$

\section{ASSOCIATED CONTENT}

Supporting Information. The Supporting Information is available free of charge on the ACS Publications website.

All experimental procedures, analysis, compound characterization data, and details of biological assays (PDF)

\section{AUTHOR INFORMATION}

\section{Corresponding Author}

Myles Smith - Department of Biochemistry, UT Southwestern Medical Center, Dallas, Texas 75390; orcid.org/0000-00020231-0059; Email: myles.smith@utsouthwestern.edu. 
Table 2. Biological investigations of synthetic spiroindimicins, lynamicins, and analogues

\begin{tabular}{|c|c|c|c|c|c|c|}
\hline \multirow[b]{2}{*}{ Compound } & \multicolumn{4}{|c|}{ Antiparasitic Activity } & \multicolumn{2}{|c|}{ Selectivity } \\
\hline & T. brucei $\mathrm{EC}_{50}(\mu \mathrm{M})$ & $\begin{array}{c}\text { P. falciparum 3D7 } \\
\mathrm{EC}_{50}(\mu \mathrm{M})\end{array}$ & $\begin{array}{l}\text { P. falciparum Dd2 } \\
\mathrm{EC}_{50}(\mu \mathrm{M})\end{array}$ & $\begin{array}{l}\text { L. amazonensis } \mathrm{EC}_{50} \\
(\mu \mathrm{M})\end{array}$ & RAW CC $50(\mu \mathrm{M})$ & HepG2 $\mathrm{CC}_{50}(\mu \mathrm{M})$ \\
\hline$( \pm)-3$ & $7.5 \pm 1.1$ & $2.8 \pm 0.49$ & $4.2 \pm 0.11$ & $1.4 \pm 0.35$ & $5.5 \pm 0.41$ & $10 \pm 1.2$ \\
\hline (S)-3 & $11 \pm 1.2$ & $3.9 \pm 0.81$ & $6.6 \pm 0.12$ & $1.3 \pm 0.33$ & $>10$ & $>10$ \\
\hline$(R)-\mathbf{3}$ & $11 \pm 1.2$ & $4.8 \pm 1.2$ & $7.1 \pm 0.33$ & $5.3 \pm 1.1$ & $>10$ & $>10$ \\
\hline$( \pm)-10$ & $7.1 \pm 1.2$ & n.t. & n.t. & $4.5 \pm 0.98$ & $8.1 \pm 0.38$ & $>10$ \\
\hline$( \pm)-36$ & $12 \pm 1.1$ & $4.4 \pm 0.93$ & $7.1 \pm 0.83$ & $6.3 \pm 1.2$ & $9.3 \pm 0.67$ & $>10$ \\
\hline$( \pm)-37$ & $3.2 \pm 0.64$ & $3.7 \pm 0.90$ & $5.5 \pm 0.51$ & $6.0 \pm 1.2$ & $>10$ & $>10$ \\
\hline 12 & $8.3 \pm 1.0$ & $>10$ & n.t. & $>10$ & $>10$ & $>10$ \\
\hline 13 & $8.2 \pm 0.45$ & $>10$ & n.t. & $8.9 \pm 0.9$ & $>10$ & $>10$ \\
\hline 21 & $0.37 \pm 0.073$ & $0.79 \pm 0.11$ & $1.0 \pm 0.030$ & $4.5 \pm 0.26$ & $3.4 \pm 1.1$ & $4.6 \pm 1.1$ \\
\hline
\end{tabular}

${ }^{a}$ Data represent the mean $\mathrm{EC}_{50} \pm$ standard error for 3 biological replicates. $\mathrm{EC}_{50}$ calculations for each biological replicate were based on data from technical triplicates. n.t. $=$ not tested

\section{Authors}

Zhen Zhang - Department of Biochemistry, UT Southwestern Medical Center, Dallas, Texas 75390, United States; orcid.org/0000-0001-9866-4523

Sneha Ray - Department of Biochemistry, UT Southwestern Medical Center, Dallas, Texas 75390, United States; http://orcid.org/0000-0001-6649-956X

Leah Imlay - Department of Biochemistry, UT Southwestern Medical Center, Dallas, Texas 75390, United States;

Lauren T. Callaghan - Department of Biochemistry, UT Southwestern Medical Center, Dallas, Texas 75390, United States;

Hanspeter Niederstrasser - Department of Biochemistry, UT Southwestern Medical Center, Dallas, Texas 75390, United States,

Prema Latha Mallipeddi - Department of Biochemistry, UT Southwestern Medical Center, Dallas, Texas 75390, United States;

Bruce A. Posner - Department of Biochemistry, UT Southwestern Medical Center, Dallas, Texas 75390, United States;

Dawn M. Wetzel - Department of Pediatrics and Department of Biochemistry, UT Southwestern Medical Center, Dallas, Texas 75390, United States; orcid.org/0000-00023990-7043

Margaret A. Phillips - Department of Biochemistry, UT Southwestern Medical Center, Dallas, Texas 75390, United States; orcid.org/0000-0001-5250-5578

Notes

The authors declare no competing financial interest.

\section{ACKNOWLEDGMENT}

This work was financially supported by UT Southwestern through the W. W. Caruth Jr. Scholarship. Funding from the Welch Foundation to M.W.S (I-2045) and M.A.P (I-1257) is gratefully acknowledged. This work was also partially funded by the NIH grants, R01AI103947 (to M.A.P),
R01AI146349 (to D.M.W.), and 1S10OD026758-01 (to B.A.P.), as well as by the CCRAC Early Investigator Award, 2019 Harrington Scholar-Innovator Award, and 2020 UTSW Pilot Synergy Grant (all to D.M.W.). We thank Dr. Fan Xu for attempting electrochemical and photoredox spirocyclizations of $\mathbf{1 2}$ and its protected variants. We are grateful to Prof. Changseng Zhang, Dr. Liang Ma, and Wenjun Zhang (South China University of Oceanology) for providing spectra and an authentic sample of SPM A, and Prof. Peter Kündig (Université de Genève) for providing chiral NHC precursors. We thank the Tambar, Ready, Qin, DeBrabander, Chen, and Falck groups (UT Southwestern) for generous access to equipment and chemicals, as well as helpful discussions, and Dr. Feng Lin for assistance with NMR studies.

\section{REFERENCES}

(1) For reviews, see: Ryan, K. S.; Drennan, C. L. Divergent Pathways in the Biosynthesis of Bisindole Natural Products. Chem. Biol. 2009, 16, 351-364. (b) Nakano, H.; Omura, S. Chemical biology of natural indolocarbazole products: 30 years since the discovery of staurosporine. J. Antibiot. 2009, 62, 17-26.

(2) Spiroindimicin isolations: (a) Zhang, W.; Liu, Z.; Li, S.; Yang, T.; Zhang, Q.; Ma, L.; Tian, X.; Zhang, H.; Huang, C.; Zhang, S.; Ju, J.; Shen, Y.; Zhang, C. Spiroindimicins A-D: New Bisindole Alkaloids from a Deep-Sea-Derived Actinomycete. Org. Lett. 2012, 14, 3364 3367. (b) Paulus, C.; Rebets, Y.; Tokovenko, B.; Nadmid, S.; Terekhova, L. P.; Myronovskyi, M.; Zotchev, S. B. Rückert, C.; Braig, S.; Zahler, S.; Kalinowski, J.; Luzhetskyy, A. New natural products identified by combined genomics-metabolomics profiling of marine Streptomyces sp. MP131-18. Sci. Rep. 2017, 7, 42382. (c) Liu, Z.; Ma, L.; Zhang, L.; Zhang, W.; Zhu, Y.; Chen, Y.; Zhang, W.; Zhang, C. Functional characterization of the halogenase $\mathrm{SpmH}$ and discovery of new deschloro-tryptophan dimers. Org. Biomol. Chem. 2019, 17, 1053-1057.

(3) McArthur, K. A.; Mitchell, S. S.; Tsueng, G.; Rheingold, A.; White, D. J.; Grodberg, J.; Lam, K. S.; Potts, B. C. M. Lynamicins AE, Chlorinated Bisindole Pyrrole Antibiotics from a Novel Marine Actinomycete. J. Nat. Prod. 2008, 71, 10, 1732-1737.

(4) Ma, L.; Zhang, W.; Zhu, Y.; Guangtao Zhang, G.; Zhang, H. Zhang. Q.; Zhang, L. Yuan, C.; Zhang, C. Identification and characterization of a biosynthetic gene cluster for tryptophan dimers in deep seaderived Streptomyces sp. SCSIO 03032. Appl. Microbiol. Biotechnol. 2017, 101, 6123-6136.

(5) For methods targeting the spiroindimicins, see: (a) Nandi, R. K.; Guillot, R.; Kouklovsky, C.; Vincent, G. Synthesis of 3,3-Spiroindolines via $\mathrm{FeCl}_{3}$-Mediated Cyclization of Aryl- or Alkene-Containing 3-Substituted N-Ac Indoles. Org. Lett. 2016, 18, 1716-1719. (b) 
Singh, B.; Bankar, S. K.; Kumar, K.; Ramasastry, S. S. V. Palladiumcatalysed 5-endo-trig allylic (hetero)arylation. Chem. Sci. 2020, 11, 4948-4953.

(6) Blair, L. M.; Sperry, J. Total syntheses of $( \pm)$-spiroindimicins B and $\mathrm{C}$ enabled by a late-stage Schöllkopf-Magnus-Barton-Zard (SMBZ) reaction. Chem. Commun. 2016, 52, 800-802.

(7) For reviews, see: Field, M. C.; Horn, D.; Fairlamb, A. H.; Ferguson, M. A.; Gray, D. W.; Read, K. D.; De Rycker, M.; Torrie, L. S.; Wyatt, P. G.; Wyllie, S.; Gilbert, I. H. Anti-trypanosomatid drug discovery: an ongoing challenge and a continuing need. Nat. Rev. Microbiol. 2017, 15, 217-231. (b) Phillips, M. A.; Burrows, J. N.; Manyando, C.; van Huijsduijnen, R. H.; Van Voorhis, W. C.; Wells, T. N. C. Malaria. Nat. Rev. Dis. Primers 2017, 3, 17050

(8) For pertinent reviews, see: (a) Quasdorf, K. W.; Overman, L. E. Catalytic enantioselective synthesis of quaternary carbon stereocentres. Nature 2014, 516, 181-191. (b) Zheng, C.; You, S.-L. Catalytic Asymmetric Dearomatization by Transition-Metal Catalysis: A Method for Transformations of Aromatic Compounds. Chem 2016, 1, 830-857. (c) Li, C.; Ragab, S. S.; Liu, G.; Tang, W. Enantioselective formation of quaternary carbon stereocenters in natural product synthesis: a recent update. Nat. Prod. Rep. 2020, 37, 276-292. (d) Zheng, C.; You, S.-L. Advances in Catalytic Asymmetric Dearomatization. ACS Cent. Sci. 2021, 7, 432-444.

(9) Sigala, I.; Ganidis, G.; Thysiadis, S.; Zografos, A. L.; Giannakouros, T.; Sarli, V.; Nikolakaki, E. Lynamicin D an antimicrobial natural product affects splicing by inducing the expression of SR protein kinase. Bioorg. Med. Chem. 2017, 25, 1622-1629.

(10) For reviews, see: (a) Gutekunst, W. R.; Baran, P. S. C-H functionalization logic in total synthesis. Chem. Soc. Rev. 2011, 40, 1976 1991. (b) Yamaguchi, J.; Yamaguchi, A. D.; Itami, K. C-H Bond Functionalization: Emerging Synthetic Tools for Natural Products and Pharmaceuticals. Angew. Chem. Int. Ed. 2012, 51, 8960-9009. (c) Sinha, S. K.; Zanoni, G.; Maiti, D. Natural Product Synthesis by C-H Activation. Asian J. Org. Chem. 2018, 7, 1178-1192. (d) Abrams, D. J.; Provencher, P. A.; Sorensen, E. J. Recent applications of C-H functionalization in complex natural product synthesis. Chem. Soc. Rev. 2018, 47 , 8925-8967. (e) Lam, N. Y. S.; Wu, K.; Yu, J.-Q. Advancing the Logic of Chemical Synthesis: $\mathrm{C}-\mathrm{H}$ Activation as Strategic and Tactical Disconnections for $\mathrm{C}-\mathrm{C}$ Bond Construction. Angew. Chem. Int. Ed. 2021, Early View, DOI: 10.1002/anie.202011901.

(11) Khusnutdinov, R. I.; Baiguzina, A. R.; Mukminov, R. R.; Akhmetov, I. V.; Gubaidullin, I. M.; Spivak, S. I.; Dzhemilev, U. M. New Synthesis of Pyrrole-2-carboxylic and Pyrrole-2,5-dicarboxylic Acid Esters in the Presence of Iron-Containing Catalysts. Russ. J. Org. Chem. 2010, 46, 1053-1059.

(12) Fürstner, A.; Krause, A.; Thiel, O. R. Efficient relay syntheses and assessment of the DNA-cleaving properties of the pyrrole alkaloid derivatives permethylstorniamide A, lycogalic acid A dimethyl ester, and the halitulin core. Tetrahedron 2002, 58, 6373-6380.

(13) Johansson Seechurn, C. C. C.; Sivakumar, V.; Satoskar, D.; Colacot, T. J. Iridium-Catalyzed C-H Borylation of Heterocycles Using an Overlooked 1,10-Phenanthroline Ligand: Reinventing the Catalytic Activity by Understanding the Solvent-Assisted Neutral to Cationic Switch. Organometallics 2014, 33, 3514-3522.

(14) Walker, S. D.; Barder, T. E.; Martinelli, J. R.; Buchwald, S. L. A Rationally Designed Universal Catalyst for Suzuki-Miyaura Coupling Processes. Angew. Chem. Int. Ed. 2004, 43, 1871-1876.

(15) For a similar pyrrole dealkoxycarbonylations, see: (a) Boger, D. L.; Patel, M. Total synthesis of prodigiosin, prodigiosene, and desmethoxyprodigiosin: Diels-Alder reactions of heterocyclic azadienes and development of an effective palladium(II)-promoted 2,2'-bipyrrole coupling procedure. J. Org. Chem. 1988, 53, 1405-1415. (b) Rana, A.; Kumar, B. S.; Panda, P. K. $\beta$-Decamethoxysapphyrin and Its $N$-Benzyl Analogue. Org. Lett. 2015, 17, 3030-3033

(16) Attempts to transform indolocarbazole 21 to a 5-membered spirooxindole revelant to SPM D via treatment with oxidants delivered 22.

(17) Skolc, D.; Ates, A.; Jnoff, E.; Valade, A. Preparation of isoindoline derivatives D1 pos. allosteric modulators. PCT Int. Appl. WO 2016055482 A1, April 14, 2016.

(18) For the preparation of the monoiodide precursor to 27, see: Hasse, K.; Willis, A. C.; Banwell, M. G. Modular Total Syntheses of
Lamellarin G Trimethyl Ether and Lamellarin S. Eur. J. Org. Chem. 2011, 88-99.

(19) Treatment of desiodo-30 with several oxidants to induce spirocyclization to $\mathbf{3 1}$ proved unsuccessful.

(20) Wu, K.-J.; Dai, L.-X; You, S.-L. Palladium(0)-Catalyzed Dearomative Arylation of Indoles: Convenient Access to Spiroindolenine Derivatives. Org. Lett. 2012, 14, 3772-3775. These authors report a single example of enantioselective spirocyclization, proceeding in $61 \%$ ee with a diastereomer of $\mathbf{L} \mathbf{3}$ as ligand.

(21) Spiroindolenine 31 was stable to heating in toluene at $90{ }^{\circ} \mathrm{C}$ for $40 \mathrm{~h}$, as well as in the presence of $\mathrm{Cs}_{2} \mathrm{CO}_{3}\left(90^{\circ} \mathrm{C}, 16 \mathrm{~h}\right)$. Partial decomposition occurs in the presence of both base and Pd catalyst at this temperature $(16 \mathrm{~h})$, but no indole $\mathbf{3 1 A}$ is formed.

(22) For reviews on Pd-PEPPSI precatalysts, see: (a) Organ, M. G.; Chass, G. A.; Fang, D.-C.; Hopkinson, A. C.; Valente, C. Pd-NHC (PEPPSI) Complexes: Synthetic Utility and Computational Studies into Their Reactivity. Synthesis 2008, 2776-2797; (b) Valente, C.; Çalimsiz, S.; Hoi, K. H.; Mallik, D.; Sayah, M.; Organ, M. G. The Development of Bulky Palladium NHC Complexes for the Most-Challenging Cross-Coupling Reactions. Angew. Chem. Int. Ed. 2012, 51, 33143332.

(23) SIPHOS-PE ligand: Zhang, W.; Wang, L.-X.; Shi, W.-J.; Zhou, Q.-L. Copper-Catalyzed Asymmetric Ring Opening of Oxabicyclic Alkenes with Grignard Reagents. J. Org. Chem. 2005, 70, 3734-3736.

(24) For a recent report of a related asymmetric process incorporating an alkyne partner, see: (a) Chu, H.; Cheng, J.; Yang, J.; Guo, Y.-L.; Zhang, J. Asymmetric Dearomatization of Indole by Palladium/PCPhos-Catalyzed Dynamic Kinetic Transformation. Angew. Chem. Int. Ed. 2020, 59, 21991-21996. For related enantioselective Pd-catalyzed cyclizations of phenols, see: (b) Rousseaux, S.; García-Fortanet, J.; Del Aguila Sanchez, M. A.; Buchwald, S. L. Palladium(0)-Catalyzed Arylative Dearomatization of Phenols. J. Am. Chem. Soc. 2011, 133, 9282 9285. (c) Xu, R.-Q.; Gu, Q.; Wu, W.-T.; Zhao, Z.-A.; You, S.-L. Construction of Erythrinane Skeleton via $\mathrm{Pd}(0)$-Catalyzed Intramolecular Dearomatization of para-Aminophenols. J. Am. Chem. Soc. 2014, 136, 15469-15472. (d) Du, K.; Guo, P.; Chen, Y.; Cao, Z.; Wang, Z.; Tang, W. Enantioselective Palladium-Catalyzed Dearomative Cyclization for the Efficient Synthesis of Terpenes and Steroids. Angew. Chem. Int. Ed. 2015, 54, 3033-3037. (e) Zhao, G.; Xu, G.; Qian, C.; Tang, W. Efficient Enantioselective Syntheses of (+)-Dalesconol A and B. J. Am. Chem. Soc. 2017, 139, 3360-3363. (f) Du, K.; Yang, H.; Guo, P.; Feng, L.; Xu, G. Qinghai Zhou, Q.; Chung, L. W.; Tang, W. Efficient syntheses of $(-)$-crinine and $(-)$-aspidospermidine, and the formal synthesis of (-)-minfiensine by enantioselective intramolecular dearomative cyclization. Chem. Sci. 2017, 8, 6247-6256. For organocatalyzed asymmetric indole C-3 arylation to indolenines, see (g) Zhang, Y.-C.; Zhao, J.-J.; Jiang, F.; Sun, S.-B.; Shi, F. Organocatalytic Asymmetric Arylative Dearomatization of 2,3- Disubstituted Indoles Enabled by Tandem Reactions. Angew. Chem. Int. Ed. 2014, 53, 13912-13915. (h) Wang, Y.; Sun, M.; Yin, L.; Shi, F. Catalytic Enantioselective Arylative Dearomatization of 3-Methyl-2-vinylindoles Enabled by Reactivity Switch. Adv. Synth. Catal. 2015, 357, 4031-4040.

(25) For other enantioselective indole to indolenine transformations, see: (a) Trost, B. M.; Quancard, J. Palladium-Catalyzed Enantioselective C-3 Allylation of 3-Substituted-1 $H$-Indoles Using Trialkylboranes. J. Am. Chem. Soc. 2006, 128, 6314-6315. (b) García-Fortanet, J.; Kessler, F.; Buchwald, S. L. Palladium-Catalyzed Asymmetric Dearomatization of Naphthalene Derivatives. J. Am. Chem. Soc. 2009, 131, 66766677. (c) Wu, Q.-F.; He, H.; Liu, W.-B.; You, S.-L. Enantioselective Construction of Spiroindolenines by Ir-Catalyzed Allylic Alkylation Reactions. J. Am. Chem. Soc. 2010, 132, 11418-11419. (d) Liu, Y.; Du, H. Pd-Catalyzed Asymmetric Allylic Alkylations of 3-Substituted Indoles Using Chiral P/Olefin Ligands. Org. Lett. 2013, 15, 740-743. (e) Romano, C.; Jia, M.; Monari, M.; Manoni, E.; Bandini, M. Metal-Free Enantioselective Electrophilic Activation of Allenamides: Stereoselective Dearomatization of Indoles. Angew. Chem. Int. Ed. 2014, 53, 13854-13857. (f) Liu, Z.-S.; Li, W.-K.; Kang, T.-R.; He, L.; Liu, Q.Z. Palladium-Catalyzed Asymmetric Cycloadditions of Vinylcyclopropanes and in Situ Formed Unsaturated Imines: Construction of Structurally and Optically Enriched Spiroindolenines. Org. Lett. 2015, 17, 150-153. (g) James, M. J.; Cuthbertson, J. D.; O’Brien, P.; Taylor, R. 
J. K.; Unsworth, W. P. Silver(I)- or Copper(II)-Mediated Dearomatization of Aromatic Ynones: Direct Access to Spirocyclic Scaffolds. Angew. Chem. Int. Ed. 2015, 54, 7640-7643. (h) Zhou, Y.; Xia, Z.-L.; Gu, Q.; You, S.-L. Chiral Phosphoric Acid Catalyzed Intramolecular Dearomative Michael Addition of Indoles to Enones. Org. Lett. 2017, 19, 762-765. (i) Magné, V.; Marinetti, A.; Gandon, V.; Voituriez, A.; Guinchard, X. Synthesis of Spiroindolenines via Regioselective Gold (I)-Catalyzed Cyclizations of $N$-Propargyl Tryptamines. Adv. Synth. Catal. 2017, 359, 4036-4042. (j) Wang, Y.; Zheng, C.; You, S.-L. Iridium-Catalyzed Asymmetric Allylic Dearomatization by a Desymmetrization Strategy. Angew. Chem. Int. Ed. 2017, 56, 15093-15097. (k) Xia, Z.-L.; Zheng, C.; Wang, S.-G.; You, S.-L. Catalytic Asymmetric Dearomatization of Indolyl Dihydropyridines through an Enamine Isomerization/Spirocyclization/Transfer Hydrogenation Sequence. Angew. Chem. Int. Ed. 2018, 57, 2653-2656. (1) Gao, R.-D.; Ding, L.; Zheng, C.; Dai, L.-X.; You, S.-L. Palladium(0)-Catalyzed Intermolecular Asymmetric Allylic Dearomatization of Polycyclic Indoles. Org. Lett. 2018, 20, 748-751. (m) Trost, B. M.; Bai, W.-J.; Hohn, C.; Bai, Y.; Cregg. J. J. Palladium-Catalyzed Asymmetric Allylic Alkylation of 3-Substituted $1 H$-Indoles and Tryptophan Derivatives with Vinylcyclopropanes. J. Am. Chem. Soc. 2018, 140, 6710-6717. (n) Huang, L.; Cai, Y.; Zhang, H.-J.; Zheng, C.; Dai, L.-X.; You, S.-L. Highly Diastereo- and Enantioselective Synthesis of Quinuclidine Derivatives by an Iridium-Catalyzed Intramolecular Allylic Dearomatization Reaction. CCS Chem. 2019, 1, 106-116. (o) Becker, A.; Grugel, C. P.; Breit, B. Rhodium-Catalyzed Stereoselective Cyclization of 3-Allenylindoles and $N$-Allenyltryptamines to Functionalized Vinylic Spiroindolenines. Org. Lett. 2021, ASAP, DOI: 10.1021/acs.orglett.1c01234. For a Pdcatalyzed asymmetric enamine arylation to indolenines, see: (p) Liang, R.-X.; Zhong, C.; Liu, Z.-H.; Yang, M.; Tang, H.-W.; Chen, J.-F.; Yang, Y.-F.; Jia, Y.-X. Enantioselective Arylation of Tetrasubstituted
Enamines: Access to Enantioenriched Indolenine and 1H-Indole Derivatives. ACS Catal. 2021, 11, 1827-1832.

(26) (a) Braga, M. V.; de Souza, W. Effects of protein kinase and phosphatidylinositol-3 kinase inhibitors on growth and ultrastructure of Trypanosoma cruzi. FEMS Microbiol. Lett. 2006, 256, 209-216. (b) Cartuche, L.; Ines Sifaoui, I.; López-Arencibia, A.; Bethencourt-Estrella, C. J.; San Nicolás-Hernández, D.; Lorenzo-Morales, J.; Piñero, J. E.; Díaz-Marrero, A. R.; Fernández, J. J. Antikinetoplastid Activity of Indolocarbazoles from Streptomyces sanyensis. Biomolecules 2020, 10,657 .

(27) The clinical candidate acoziborole (currently in Phase III) has an $\mathrm{EC}_{50}$ value of $0.6 \mu \mathrm{M}$ against $T$. brucei, see: (a) Dickie, E. A.; Giordani, F.; Gould, M. K.; Mäser, P.; Burri, C.; Mottram, J. C.; Rao, S. P. S.; Barrett, M. P. New Drugs for Human African Trypanosomiasis: A Twenty First Century Success Story. Trop. Med. Infect. Dis. 2020, 5,29 . The bar for a clinical antimalarial candidate is significantly higher, typically $\mathrm{EC}_{50} \leq 10 \mathrm{nM}$ is desirable, see: (b) Ashton; T. D.; Devine, S. M.; Möhrle, J. J.; Laleu, B.; Burrows, J. N.; Charman, S. A.; Creek, D. J.; Sleebs, B. E. The Development Process for Discovery and Clinical Advancement of Modern Antimalarials. J. Med. Chem. 2019, $62,10526$.

(28) The approved leishmaniasis drug miltefosine has $\mathrm{EC}_{50}$ values of $6.83-10.12 \mu \mathrm{M}$ and $1.2 \mu \mathrm{M}$ against intracellular L. mexicana and extracellular L. amazonensis, respectively, see: (a) Sindermann, H.; Croft, S.L.; Engel, K.R.; W. Bommer H. J. Eibl, H. J. Unger, C. Engel, J. Miltefosine (Impavido): the first oral treatment against leishmaniasis. Med. Microbiol. Immunol. 2004, 193, 173-180. (b) Ullah, I.; Gahalawat, S.; Booshehri, L.M.; Niederstrasser, H.; Majumdar, S.; Leija, C.; Bradford, J. M.; Hu, B.; Ready, J. M.; Wetzel, D. M. An antiparasitic compound from the Medicines for Malaria Venture Pathogen Box promotes Leishmania tubulin polymerization. ACS Infect Dis. 2020, 6, 2057-2072. 
Table of Contents artwork:

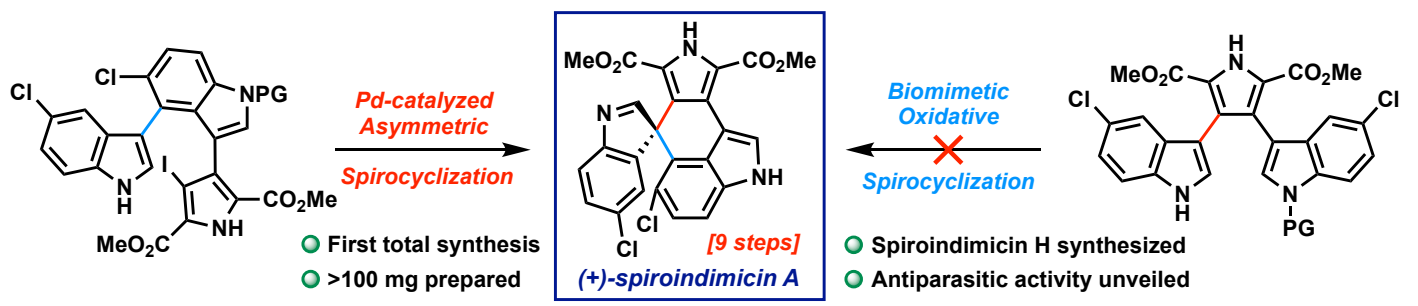

